\section{Face mask use in the communi- ty and cutaneous reactions to them during the COVID-19 pandemic: results of a national survey in Italy}

\author{
Simone Cazzaniga, ${ }^{1,2}$ Elena Pezzolo, ${ }^{1,3}$ \\ Paolo Colombo, ${ }^{4}$ Luigi Naldi ${ }^{1,3}$ \\ ${ }^{1}$ Study Center of the Italian Group for \\ Epidemiologic Research in Dermatology \\ (GISED), Bergamo, Italy; ${ }^{2}$ Department \\ of Dermatology, Inselspital University \\ Hospital of Bern, Bern, Switzerland; \\ ${ }^{3}$ Department of Dermatology, San \\ Bortolo Hospital, Vicenza, Italy; ${ }^{4}$ DOXA \\ institute, Italy
}

\begin{abstract}
To mitigate the outbreak of coronavirus disease 2019 pandemic, many countries have imposed the public use of face masks. We investigated attitudes and skin reactions in the Italian individuals wearing face masks during the pandemic. A cross-sectional survey on a random sample $(\mathrm{N}=1001)$ of the Italian adult population was conducted in May 2020 by the Italian Group for Epidemiological Research in Dermatology, and the Gallup International Association. Univariable and multivariable regression analysis were used to estimate the odds ratios and their $95 \%$ confidence intervals. Most individuals $(72.5 \%)$ wore a mask, $56.5 \%$ used a surgical mask and 53.0\% a disposable mask. One-third changed the mask at least once a day, two-thirds kept a distance of at least one meter from each other, $50 \%$ washed their hands before wearing a mask, and $17.6 \%$ adopted multiple hygienic behaviors. Twenty percent of individuals reported redness, swelling, itching or erosions in the skin area of mask contact; the risk of this reaction was associated with young age, the use of respirators and a history of pre-existing contact eczema, psoriasis or atopic dermatitis. Health educational programs may improve compliance with combined preventive measures and reduce skin reactions.
\end{abstract}

\section{Introduction}

The coronavirus disease 2019 (COVID19) pandemic, caused by severe acute respiratory syndrome coronavirus 2 (SARSCoV-2), has severely affected the general community. ${ }^{1}$ As a result, many countries have implemented infection control mea- sures to prevent disease spread, including universal masking. The public use of face masks has been increasingly recommended by the World Health Organization (WHO) and the US Centers for Disease Control and Prevention (CDC). ${ }^{2}$ In countries with a high population transmission and prevalence of SARS-CoV-2 infection, like Italy, the public use of face masks has been made compulsory, in combination with physical distancing and hand hygiene.

Face masks are personal protective equipment (PPE), which work by providing a physical barrier between the mouth and the nose of the wearer and the surrounding environment.

There is ample evidence that asymptomatic individuals or clinically undetected carriers are the major source of the infection transmission. ${ }^{3,4}$ Experimental studies suggest a role of face masks in both protecting the wearer from contracting ${ }^{5,6}$ or from transmitting infections. ${ }^{7}$ In a re-analysis of two trials, surgical masks and N95 respirators, when worn by healthcare workers, have been documented to be effective in protecting against respiratory infection in a clinical setting. ${ }^{8}$ Community-based randomized clinical trials have yielded less convincing results. ${ }^{9-11}$ However, it is largely accepted that surgical masks or even homemade cloth face masks can concur with hand washing and distancing to reduce the spreading of respiratory infection..$^{5,12}$

Little is known about attitudes related to face mask use. ${ }^{13}$ An incorrect use and disposal of face masks, without following standards of wearing and of sterilizing and cleaning protective equipment, may in principle increase the rate of COVID-19 transmission. In addition, although face masks are generally well tolerated for short periods of time, with prolonged use they can be irritating for the skin and mucous membranes.

The purpose of this study was to evaluate face mask associated attitudes and possible skin reactions to them in a large sample of the general Italian population during the COVID-19 pandemic.

\section{Materials and methods}

\section{Study design}

This was a survey on a random sample of the Italian adult population conducted in May 2020 by the Italian Group for Epidemiological Research in Dermatology (GISED), in collaboration with the Italian branch of the Gallup International Association (DOXA), and assessed through Computer Assisted Telephone Interviewing
Correspondence:Elena Pezzolo, San Bortolo Hospital, Viale Ferdinando Rodolfi 37, Vicenza, Italy. Tel.: +39.0444757130 .

E-mail: elena.pezzolo@gmail.com

Key words: community; COVID-19; face mask; skin reactions; pandemic

Contributions: Conceptualization: LN, SC, EP. Data curation: LN, SC, PC. Formal analysis: SC. Investigation: $\mathrm{SC}, \mathrm{LN}, \mathrm{EP}$ Methodology: SC, LN, PC. Project administration: LN. Resources: LN, PC. Software: SC. Supervision: LN. Validation: SC, LN. Visualization: EP, SC, LN. Writing (original draft): EP. Writing (review and editing): EP, SC, LN.

Conflict of interest: The authors declare no potential conflict of interest.

Funding: None.

Ethical approval and consent to participate: They were obtained for each participant to the study.

Availability of data and material: Data and materials are available by the authors.

Please cite this article as: Cazzaniga $S$, Pezzolo E, Colombo P, Naldi L. Face mask use in the community and cutaneous reactions to them during the COVID-19 pandemic: results of a national survey in Italy. Dermatol Rep 2022;14:9394.

Received for publication: 4 October 2021. Accepted for publication: 12 October 2021.

This work is licensed under a Creative Commons Attribution-NonCommercial 4.0 International License (CC BY-NC 4.0).

๑Copyright: the Author(s), 2022

Licensee PAGEPress, Italy

Dermatology Reports 2022; 14:9394

doi:10.4081/dr.2022.9394

Publisher's note: All claims expressed in this article are solely those of the authors and do not necessarily represent those of their affiliated organizations, or those of the publisher, the editors and the reviewers. Any product that may be evaluated in this article or claim that may be made by its manufacturer is not guaranteed or endorsed by the publisher.

(CATI).${ }^{14}$ More specifically, a randomized sampling strategy without replacement was adopted with stratification by age, sex and geographical distribution of the Italian adult population. ${ }^{15}$ People were contacted by phone and asked to participate in the survey. A target sample of at least 1,000 subjects was planned before starting the study. 


\section{Collected variables}

The following socio-demographic variables were collected: age, gender, residence area, nationality, educational level, current occupation, marital status and children $<18$ years. The survey on face mask use during the COVID-19 pandemic included nine different questions: type of face mask mostly used, frequency of use, frequency of change, concomitant hygienic behaviours, modality of face mask storage when not in use, occurrence of skin reactions in the area of face mask use, consultation of a doctor/pharmacist and treatments in case of a reaction.

In addition, the lifetime reported diagnoses of dermatological conditions, including contact eczema, atopic dermatitis, psoriasis or other diagnoses, was collected. The full survey questionnaire is available as an additional online material.

\section{Statistical analysis}

For descriptive purposes, data are presented as means with standard deviations (SD) or absolute numbers with percentages, for continuous and nominal variables, respectively. One-sample binomial proportion test and one-sample t-test were used to compare gender and age distribution of participants with known Italian census data. ${ }^{14}$

Univariable and multivariable logistic regression analysis, including age, gender, geographic area and educational level as potential confounder factors, was used to assess associations between selected variables and face mask-related skin reactions. The strength of association was expressed in terms of odds ratios (OR) along with their $95 \%$ confidence intervals $(\mathrm{CI})$ and $\mathrm{p}$-values. All tests were considered statistically significant at $p$-value $<0.05$. Analyses were performed using SPSS software version 26.0 (IBM Corporation, Armonk, NY, USA).

\section{Results}

\section{Study population}

From a total of 1,803 people contacted, 1,001 participants ( $55 \%$ of the total; $51.8 \%$ women, mean age $50.4 \pm 16.8$ years) completed the phone survey. Most people worked as employees $(27.8 \%)$ or were retired $(15.7 \%)$, had upper secondary $(48.4 \%)$ or university degree $(36.5 \%)$, were married or in a domestic partnership $(66.7 \%) .28 .9 \%$ of the interviewed people had children (Table 1).

The gender distribution of participants was similar to the Italian adult population census data $(51.8 \%, \mathrm{p}=0.98)$, although the mean age of our sample was slightly lower compared to the general population (51.8 years, $\mathrm{p}=0.01$ ).

The modalities of face mask use during the COVID-19 pandemic are shown in Table 2. Most subjects worn a face mask either every time when out $(72.5 \%)$ or only in the presence of other people $(23.3 \%)$. Among those who used a mask, 56.5\% mainly wore a surgical mask, while $24.5 \%$ a respirator (N95 or FFP2-FFP3 mask type). More than half of people $(53.0 \%)$ used a disposable mask, and most participants changed the mask at least once a day $(28.7 \%), 2-3$ times a week $(26.0 \%)$ or at least once a week (26.0\%). Most subjects also kept a distance of at least one meter from other people $(66.5 \%)$ and regularly washed their hands before wearing a mask (50.5\%). However only $17.6 \%$ of participants adopted multiple concomitant hygienic behaviors including hand washing plus social distance plus avoidance of touching the external surface of the mask with hands, or at least hand washing plus social distance $(11.6 \%)$. The most common modality of mask storage when not in use was in a cabinet or shelf, inside $(34.5 \%)$ or not inside

\section{Table 1. Sociodemographic information of the study population.}

\begin{tabular}{|c|c|c|c|}
\hline & & $\mathbf{N}$ & $\%$ \\
\hline Gender & $\begin{array}{l}\text { Men } \\
\text { Women }\end{array}$ & $\begin{array}{l}482 \\
519\end{array}$ & $\begin{array}{l}48.2 \\
51.8\end{array}$ \\
\hline Age (years) & $\begin{array}{l}\text { Mean, SD } \\
18-35 \\
35-49 \\
50-64 \\
65+\end{array}$ & $\begin{array}{l}50.4 \\
209 \\
260 \\
262 \\
270\end{array}$ & $\begin{array}{l}16.8 \\
20.9 \\
26.0 \\
26.2 \\
27.0\end{array}$ \\
\hline Geographic area & $\begin{array}{l}\text { Northern Italy } \\
\text { Central Italy } \\
\text { Southern Italy / Islands }\end{array}$ & $\begin{array}{l}456 \\
194 \\
351\end{array}$ & $\begin{array}{l}45.6 \\
19.4 \\
35.1\end{array}$ \\
\hline Educational level & $\begin{array}{l}\text { Master / PhD } \\
\text { Associate / bachelor } \\
\text { Upper secondary school } \\
\text { Lower secondary school } \\
\text { Elementary school / none }\end{array}$ & $\begin{array}{c}64 \\
301 \\
484 \\
140 \\
12\end{array}$ & $\begin{array}{c}6.4 \\
30.1 \\
48.4 \\
14.0 \\
1.2\end{array}$ \\
\hline Current occupation & $\begin{array}{l}\text { Business owner / manager } \\
\text { Freelancer / trader } \\
\text { Teacher } \\
\text { Employee } \\
\text { Worker / labourer } \\
\text { Housewife } \\
\text { Retired } \\
\text { Unemployed } \\
\text { Student } \\
\text { Other }\end{array}$ & $\begin{array}{c}87 \\
97 \\
31 \\
278 \\
49 \\
99 \\
157 \\
52 \\
72 \\
79\end{array}$ & $\begin{array}{c}8.7 \\
9.7 \\
3.1 \\
27.8 \\
4.9 \\
9.9 \\
15.7 \\
5.2 \\
7.2 \\
7.9\end{array}$ \\
\hline Marital status & $\begin{array}{l}\text { Unmarried } \\
\text { Married / domestic partner } \\
\text { Widow(er) } \\
\text { Divorced }\end{array}$ & $\begin{array}{c}233 \\
668 \\
38 \\
62\end{array}$ & $\begin{array}{c}23.3 \\
66.7 \\
3.8 \\
6.2\end{array}$ \\
\hline Children $<18$ years & $\begin{array}{l}\text { Yes } \\
\text { No }\end{array}$ & $\begin{array}{l}289 \\
712\end{array}$ & $\begin{array}{l}28.9 \\
71.1\end{array}$ \\
\hline
\end{tabular}

SD: standard deviation.
$(31.2 \%)$ an envelope.

Table 3 reports the occurrence of skin reactions related to face mask use; $5.7 \%$ of people declared to always have skin reactions like redness, swelling, itching or small erosions in the area of mask contact, while $12.7 \%$ only occasionally. Among these subjects, $17.5 \%$ consulted a doctor or a pharmacist for the reaction, $14.2 \%$ used local medications and $16.4 \%$ protective cosmetics in the area of reaction.

Risk factors for skin reactions to face mask use are shown in Table 4. Overall, $5.1 \%$ of participants reported a lifetime diagnosis of contact eczema, $8.0 \%$ a diagnosis of atopic dermatitis and $6.5 \%$ a diagnosis of psoriasis. Any investigated dermatological conditions, including contact eczema (adjusted $\mathrm{OR}=3.91$, 95\% CI: 2.13 7.17), psoriasis (adjusted $\mathrm{OR}=3.61,95 \%$ CI: 2.10-6.21) and atopic dermatitis (adjusted $\mathrm{OR}=2.34,95 \%$ CI: 1.41-3.88) were associated with an increased risk of skin reactions in the area of mask use. Participants with no reported history of dermatological conditions were significantly protected against skin reactions compared with those who reported a history of any dermatologi- 
cal condition (adjusted $\mathrm{OR}=0.28,95 \% \mathrm{CI}$ : 0.20-0.40). Notably, compared to surgical masks, the use of respirators was linked with a moderate increased risk of skin reactions (adjusted OR=1.62 95\% CI: 1.112.37).

\section{Discussion}

Our study shows that, during the first wave of the COVID-19 pandemic, the majority $(>70 \%)$ of Italian people showed a positive attitude towards the use of face masks, while in public, and around $18.4 \%$ of individuals reported adverse skin reactions to mask use, with the risk of such a reaction being associated with age, type of mask used and, strongly, with a pre-existing dermatological condition. Overall, participants showed a low level of compliance regarding the adoption of multiple combined preventive measures.
In spite of their large promotion and use, data are still limited concerning face mask related attitudes and skin problems in the general population during the COVID19 pandemic. In line with our results, another interview-based study, in a cohort of 1,070 Turkish people representative of the general population, found similar positive attitudes towards using masks, during the COVID-19 pandemic. ${ }^{13}$ We found a higher proportion of individuals wearing a face mask in public settings $(72.5 \%)$ compared

Table 2. Modalities of face mask use during COVID-19 pandemic in the study population.

\begin{tabular}{|c|c|c|c|}
\hline & & $\mathbf{N}$ & $\%$ \\
\hline Frequency of mask use & $\begin{array}{l}\text { Every time when out } \\
\text { Every time when out, but only if other people are present } \\
\text { Not always, it depends on the availability at the moment } \\
\text { Almost never when out } \\
\text { Never }\end{array}$ & $\begin{array}{c}726 \\
233 \\
28 \\
6 \\
8\end{array}$ & $\begin{array}{r}72.5 \\
23.3 \\
2.8 \\
0.6 \\
0.8\end{array}$ \\
\hline \multicolumn{4}{|c|}{ For those who used face mask $(n=993)$} \\
\hline Main type of mask & $\begin{array}{l}\text { Surgical mask } \\
\text { Respirator } \\
\text { Cloth mask } \\
\text { Other } \\
\text { Unknown / no answer }\end{array}$ & $\begin{array}{l}561 \\
243 \\
144 \\
15 \\
30\end{array}$ & $\begin{array}{r}56.5 \\
24.5 \\
14.5 \\
1.5 \\
3.0\end{array}$ \\
\hline Use of disposable mask & $\begin{array}{l}\text { Yes } \\
\text { No } \\
\text { Unknown }\end{array}$ & $\begin{array}{c}526 \\
394 \\
73\end{array}$ & $\begin{array}{r}53.0 \\
39.7 \\
7.4\end{array}$ \\
\hline Frequency of mask change & $\begin{array}{l}\text { Every day, several times a day } \\
\text { Every day, once a day } \\
2-3 \text { times a week } \\
\text { At least once a week } \\
\text { Less than once a week }\end{array}$ & $\begin{array}{c}80 \\
205 \\
258 \\
258 \\
192\end{array}$ & $\begin{array}{r}8.1 \\
20.6 \\
26.0 \\
26.0 \\
19.3\end{array}$ \\
\hline Concomitant hygienic behaviours* & $\begin{array}{l}\text { Hand washing or hand disinfection before wearing a mask } \\
\text { Avoidance of touching the external surface of the mask with hands } \\
\text { Keep a distance of at least one meter from other people when wearing a mask } \\
\text { None of these behaviours }\end{array}$ & $\begin{array}{l}501 \\
370 \\
660 \\
22\end{array}$ & $\begin{array}{l}50.5 \\
37.3 \\
66.5 \\
2.2\end{array}$ \\
\hline Combination of different hygienic behaviours & $\begin{array}{l}\text { Hand washing + avoidance of touching mask + distance } \\
\text { Hand washing + avoidance of touching mask } \\
\text { Hand washing + distance } \\
\text { Avoidance of touching mask + distance }\end{array}$ & $\begin{array}{c}175 \\
16 \\
115 \\
79\end{array}$ & $\begin{array}{r}17.6 \\
1.6 \\
11.6 \\
8.0\end{array}$ \\
\hline Modality of mask conservation when not in use & $\begin{array}{l}\text { In a cabinet or a shelf inside an envelope } \\
\text { In a cabinet or a shelf not inside an envelope } \\
\text { In a pocket or bag, backpack, etc, inside an envelope } \\
\text { In a pocket or bag, backpack, etc, not inside an envelope } \\
\text { Nowhere because it is a disposable mask } \\
\text { Other }\end{array}$ & $\begin{array}{c}343 \\
310 \\
102 \\
43 \\
125 \\
70\end{array}$ & $\begin{array}{r}34.5 \\
31.2 \\
10.3 \\
4.3 \\
12.6 \\
7.0\end{array}$ \\
\hline
\end{tabular}

${ }^{*}$ Multiple responses were possible.

Table 3. Occurrence of skin reactions related to face mask use and lifetime reported diagnoses of dermatological conditions in the study population.

\begin{tabular}{|c|c|c|c|}
\hline & & $\mathbf{N}$ & $\%$ \\
\hline $\begin{array}{l}\text { Skin reactions like redness, swelling, itching, } \\
\text { small erosions in the area of mask contact** }\end{array}$ & $\begin{array}{l}\text { Always } \\
\text { Occasionally } \\
\text { Never }\end{array}$ & $\begin{array}{c}57 \\
126 \\
810\end{array}$ & $\begin{array}{c}5.7 \\
12.7 \\
81.6\end{array}$ \\
\hline If yes* & $\begin{array}{l}\text { Consultation of a doctor for the reaction } \\
\text { Consultation of a pharmacist for the reaction } \\
\text { Local drugs application for the reaction } \\
\text { Protective cosmetics application for the reaction } \\
\text { No consultation or treatment performed }\end{array}$ & $\begin{array}{c}9 \\
23 \\
26 \\
30 \\
106\end{array}$ & $\begin{array}{c}4.9 \\
12.6 \\
14.2 \\
16.4 \\
57.9\end{array}$ \\
\hline
\end{tabular}

${ }^{*}$ Multiple responses were possible. ${ }^{* *}$ This mainly includes acne and skin cancer. 
with the rate of approximately $40 \%$ reported in that study. This may probably be due to the earlier adoption of most of the preventing measures in our country compared with Turkey and other European countries. ${ }^{13}$

One concern during the first wave of the Italian epidemic in late February and early March 2020, was that face mask use in the community could divert supplies from individuals at higher risk of infection like healthcare workers $(\mathrm{HCW})$, and people in the community were increasingly asked to ration and reuse masks. Based on our study, reusable face masks were adopted by nearly $40 \%$ of individuals. While community use of face coverings has increased substantially, some have raised concerns that homemade face masks may be inferior compared with commercially manufactured masks. Cloth face coverings can limit forward dispersion of exhaled air, containing potentially infectious respiratory particles in the 1to 10-micrometer range, and household textiles' performance has acceptable efficiency and breathability. ${ }^{16}$

As for any other community-wide inter- ventions, face-masking in public spaces, even when properly used, cannot afford complete protection from infection, and other basic measures such as hand hygiene in addition to physical distancing are still needed. In our study we found that twothird of people kept a social distancing of at least one-meter, and around fifty per cent people regularly washed their hands before wearing a mask; however, a minority of individuals adopted multiple hygienic behaviors such as hand washing plus social distance plus avoidance of touching the external surface of the mask with hands $(17.6 \%)$, or at least hand washing plus social distance $(11.6 \%)$.

Little is known about the most prevalent types of skin damage in face mask users. ${ }^{17}$ These may include irritant or allergic contact dermatitis, pressure $\square$ related skin conditions such as pressure urticaria, friction dermatitis, abrasions, or aggravation of underlying skin diseases, such as acne. ${ }^{18}$ Although iatrogenic dermatitis in HCWs in time of COVID-19 pandemic has been described, mask-induced dermatitis at the population level is a relatively unexplored phenomenon. ${ }^{19}$ In our study we found that around $18.4 \%$ of individuals wearing masks in the community had a persistent or occasional skin reaction, including redness, swelling, itching, and erosions in the area of mask contact. In line with the results reported in another survey that investigated the prevalence, intensity and clinical characteristics of itch related to the use of face masks, ${ }^{19}$ we found that individuals with sensitive skin and atopic predisposition, and those with pre-exiting dermatoses such as contact eczema, psoriasis or atopic dermatitis, were at a significantly higher risk of such skin reactions. As for itching-scratching, the presence of these dermatological conditions can lead to incorrect use of face masks, resulting in a reduced protection.

To the best of our knowledge, this is the first study to evaluate both attitudes and dermatological conditions in response to the use of face masks during the COVID-19 pandemic in the Italian population.

Our study has some drawbacks. It was a phone survey, and although a random sam-

Table 4. Risk factors for skin reactions related to face mask use.

\begin{tabular}{|c|c|c|c|c|c|c|c|c|c|}
\hline & & & & tion & & Crude OR & $P$ & Adjusted OR & $P$ \\
\hline & & $N$ & $\%$ & $N$ & $\%$ & $(95 \% \mathrm{Cl})$ & & $(95 \% \mathrm{CI})^{\wedge}$ & \\
\hline Sex & $\begin{array}{l}\text { Male } \\
\text { Female }\end{array}$ & $\begin{array}{l}77 \\
106\end{array}$ & $\begin{array}{l}42.1 \\
57.9\end{array}$ & $\begin{array}{l}400 \\
410\end{array}$ & $\begin{array}{l}49.4 \\
50.6\end{array}$ & $\begin{array}{c}1 \\
1.34(0.97-1.86)\end{array}$ & 0.07 & $\begin{array}{c}1 \\
1.29 \\
(0.92-1.81)\end{array}$ & 0.14 \\
\hline Age & $\begin{array}{l}<35 \\
35-49 \\
50-64 \\
65+\end{array}$ & $\begin{array}{l}63 \\
48 \\
45 \\
27\end{array}$ & $\begin{array}{l}34.4 \\
26.2 \\
24.6 \\
14.8\end{array}$ & $\begin{array}{l}144 \\
211 \\
216 \\
239\end{array}$ & $\begin{array}{l}17.8 \\
26.0 \\
26.7 \\
29.5\end{array}$ & $\begin{array}{c}3.87(2.36-6.36) \\
2.01(1.21-3.34) \\
1.84(1.11-3.07) \\
1\end{array}$ & $\begin{array}{c}<0.001 \\
0.007 \\
0.02\end{array}$ & $\begin{array}{c}3.64(2.20-6.03) \\
2.00(1.20-3.34) \\
1.89(1.13-3.15) \\
1\end{array}$ & $\begin{array}{c}<0.001 \\
0.008 \\
0.01\end{array}$ \\
\hline Educational level & $\begin{array}{l}\text { Master|PhD|Bachelor Associate } \\
\text { Upper secondary } \\
\text { Lower secondarylelemantarylnone }\end{array}$ & $\begin{array}{l}79 \\
75 \\
29\end{array}$ & $\begin{array}{l}43.2 \\
41.0 \\
15.8\end{array}$ & $\begin{array}{l}282 \\
405 \\
123\end{array}$ & $\begin{array}{l}34.8 \\
50.0 \\
15.2\end{array}$ & $\begin{array}{c}1 \\
0.66(0.47-0.94) \\
0.84(0.52-1.35)\end{array}$ & $\begin{array}{l}0.02 \\
0.48\end{array}$ & $\begin{array}{c}1 \\
0.69(0.48-0.99) \\
0.92(0.56-1.50)\end{array}$ & $\begin{array}{l}0.04 \\
0.74\end{array}$ \\
\hline Geographic area & $\begin{array}{l}\text { North } \\
\text { Center } \\
\text { South }\end{array}$ & $\begin{array}{l}82 \\
35 \\
66\end{array}$ & $\begin{array}{l}44.8 \\
19.1 \\
36.1\end{array}$ & $\begin{array}{l}373 \\
156 \\
281\end{array}$ & $\begin{array}{l}46.0 \\
19.3 \\
34.7\end{array}$ & $\begin{array}{c}1 \\
1.02(0.66-1.58) \\
1.07(0.75-1.53)\end{array}$ & $\begin{array}{l}0.93 \\
0.72 \\
\end{array}$ & $\begin{array}{c}1 \\
0.99(0.63-1.55) \\
0.97(0.67-1.41)\end{array}$ & $\begin{array}{l}0.97 \\
0.88\end{array}$ \\
\hline Type of face mask & $\begin{array}{l}\text { Surgical } \\
\text { Respirators } \\
\text { Homemade }\end{array}$ & $\begin{array}{l}90 \\
59 \\
27\end{array}$ & $\begin{array}{l}51.1 \\
33.5 \\
15.3\end{array}$ & $\begin{array}{l}471 \\
184 \\
132\end{array}$ & $\begin{array}{l}59.8 \\
23.4 \\
16.8\end{array}$ & $\begin{array}{c}1 \\
1.68(1.16-2.43) \\
1.07(0.67-1.71)\end{array}$ & $\begin{array}{l}0.006 \\
0.78\end{array}$ & $\begin{array}{c}1 \\
1.62(1.11-2.37) \\
0.98(0.60-1.59)\end{array}$ & $\begin{array}{l}0.01 \\
0.94\end{array}$ \\
\hline Use of disposable masks? & $\begin{array}{l}\text { Yes } \\
\text { No }\end{array}$ & $\begin{array}{l}97 \\
67 \\
\end{array}$ & $\begin{array}{l}59.1 \\
40.9 \\
\end{array}$ & $\begin{array}{l}429 \\
327\end{array}$ & $\begin{array}{l}56.7 \\
43.3 \\
\end{array}$ & $\begin{array}{c}1 \\
0.91(0.64-1.28)\end{array}$ & 0.57 & $\begin{array}{c}1 \\
0.95(0.67-1.36)\end{array}$ & 0.79 \\
\hline Frequency of mask change & $\begin{array}{l}\text { Every day } \\
\text { 2-3 times a week } \\
\text { At least once a week } \\
\text { Less than once a week }\end{array}$ & $\begin{array}{l}67 \\
51 \\
35 \\
30\end{array}$ & $\begin{array}{l}36.6 \\
27.9 \\
19.1 \\
16.4\end{array}$ & $\begin{array}{l}218 \\
207 \\
223 \\
162\end{array}$ & $\begin{array}{l}26.9 \\
25.6 \\
27.5 \\
20.0\end{array}$ & $\begin{array}{c}1.66(1.03-2.67) \\
1.33(0.81-2.18) \\
0.85(0.50-1.44) \\
1\end{array}$ & $\begin{array}{l}0.04 \\
0.26 \\
0.54\end{array}$ & $\begin{array}{c}1.69(1.04-2.75) \\
1.41(0.85-2.36) \\
0.95(0.55-1.62) \\
1\end{array}$ & $\begin{array}{l}0.03 \\
0.18 \\
0.84\end{array}$ \\
\hline & & agno: & f der & $\mathrm{cal} \mathrm{co}$ & ions* & & & & \\
\hline Contact eczema & & 22 & 12.0 & 27 & 3.3 & $3.96(2.20-7.13)$ & $<0.001$ & $3.91(2.13-7.17)$ & $<0.001$ \\
\hline Atopic dermatitis & & 28 & 15.3 & 52 & 6.4 & $2.63(1.61-4.30)$ & $<0.001$ & $2.34(1.41-3.88)$ & 0.001 \\
\hline Psoriasis & & 27 & 14.8 & 38 & 4.7 & $3.52(2.08-5.93)$ & $<0.001$ & $3.61(2.10-6.21)$ & $<0.001$ \\
\hline Other** & & 15 & 8.2 & 44 & 5.4 & $1.55(0.84-2.86)$ & 0.16 & $1.68(0.89-3.16)$ & 0.11 \\
\hline None & & 103 & 56.3 & 669 & 82.6 & $0.27(0.19-0.38)$ & $<0.001$ & $0.28(0.20-0.40)$ & $<0.001$ \\
\hline
\end{tabular}

CI: confidence interval, OR: odds ratio. *Multiple responses were possible (Yes vs. No). The reference category for each entry was the lack of the condition in all the other participants. **This mainly includes acne and skin cancer. ^Multiple logistic regression models including terms for age, gender, residence area and educational level. 
ple of the Italian population was collected, we cannot exclude that some degree of selfselection for participation partly influenced our results. It was, however, reassuring that the distribution of demographic variables in our sample was similar to the distribution in the general Italian population. We did not assess the reliability of self-reported data. however, experienced professional interviewers guided data collection.

\section{Conclusions}

In conclusion, our study shows that the Italian population had a positive attitude towards the use of face masks during the first wave of the COVID-19 pandemic, even if the adoption of multiple hygienic behaviors in combination was rather low. In addition, our study documents a relevant frequency of adverse skin reactions to face mask especially in people with pre-existing dermatologic diseases. Our data highlight the need for tailored health educational programs to improve patients' compliance with preventive measures and skin care during the COVID-19 pandemic. In particular, people should be educated on the optimal use of face masks and instructed about the possible onset of skin reactions and best ways to reduce their impact. More studies should be done on materials best suited for use by people experiencing skin reactions and on ways to prevent and treat those reactions.

\section{References}

1. Wiersinga WJ, Rhodes A, Cheng AC, et al. Pathophysiology, Transmission, Diagnosis, and Treatment of Coronavirus Disease 2019 (COVID19): A Review. JAMA 2020;324:78293.

2. World Health Organization. WHO coro- navirus disease (COVID-19) Dashboard. Available from: https://covid19.who.int/. Accessed 26 June 2020

3. Long QX, Tang XJ, Shi QL, et al. Clinical and immunological assessment of asymptomatic SARS-CoV-2 infections. Nat Med 2020;26:1200-4.

4. MacIntyre CR, Chughtai AA. Face masks for the prevention of infection in healthcare and community settings. BMJ 2015;350:h694.

5. Davies A, Thompson KA, Giri K, et al. Testing the efficacy of homemade masks: would they protect in an influenza pandemic? Disaster Med Public Health Prep 2013;7:413-8.

6. Lai ACK, Poon CKM, Cheung ACT. Effectiveness of face masks to reduce exposure hazards for airborne infections among general populations. J R Soc Interface 2012;9:938-48.

7. Dharmadhikari AS, Mphahlele M, Stoltz A, et al. Surgical face masks worn by patients with multidrug-resistant tuberculosis: impact on infectivity of air on a hospital ward. Am J Respir Crit Care Med 2012;185:1104-9.

8. MacIntyre CR, Chughtai AA, Rahman $B$, et al. The efficacy of medical masks and respirators against respiratory infection in healthcare workers. Influenza Other Respir Viruses 2017;11: 511-7.

9. Canini L, Andréoletti L, Ferrari P, et al. Surgical mask to prevent influenza transmission in households: a cluster randomized trial. PLoS One 2010;5:e13998.

10. Cowling BJ, Zhou Y, Ip DKM, et al. Face masks to prevent transmission of influenza virus: a systematic review. Epidemiol Infect 2010;138:449-56.

11. MacIntyre CR, Cauchemez S, Dwyer DE, et al. Face mask use and control of respiratory virus transmission in households. Emerg Infect Dis 2009;15:23341.
12. van der Sande M, Teunis P, Sabel R. Professional and home-made face masks reduce exposure to respiratory infections among the general population. PLoS One 2008;3:e2618.

13. Başer DA, Çevik M, Gümüştakim S, Başara E. Assessment of individuals' attitude, knowledge and anxiety towards COVID-19 at the first period of the outbreak in Turkey: A web-based cross-sectional survey. Int J Clin Pract 2020;74:e13622.

14. Naldi L, Colombo P, Placchesi EB, et al. PraKtis Study Centers. Study design and preliminary results from the pilot phase of the PraKtis study: self-reported diagnoses of selected skin diseases in a representative sample of the Italian population. Dermatology 2004;208:3842.

15. Italian census data. http://demo. istat.it/pop2019/index.html Accessed 2020, September, 14, 2020.

16. Konda A, Prakash A, Moss GA, et al. Aerosol Filtration Efficiency of Common Fabrics Used in Respiratory Cloth Masks. ACS Nano 2020;14:633947.

17. Bhatia R, Sindhuja T, Bhatia S, et al. Iatrogenic dermatitis in times of COVID-19: a pandemic within a pandemic. J Eur Acad Dermatol Venereol 2020;34:e563-e66.

18. Yan Y, Chen $\mathrm{H}$, Chen L, et al. Consensus of Chinese experts on protection of skin and mucous membrane barrier for health-care workers fighting against coronavirus disease 2019. Dermatol Ther 2020;33:e13310.

19. Szepietowski JC, MatusiaK L, Szepietowska M, et al. Face Mask-induced Itch: A Self-questionnaire Study of 2,315 Responders During the COVID19 Pandemic. Acta DermVenereol 2020;100:adsv00152. 